\title{
Mouse models in arrhythmogenic right ventricular cardiomyopathy
}

\section{Elisabeth M. Lodder ${ }^{1 *}$ and Stefania Rizzo ${ }^{2}$}

${ }^{1}$ Department of Experimental Cardiology, Heart Failure Research Center, Academic Medical Center, University of Amsterdam, Amsterdam, Netherlands

${ }^{2}$ Department of Cardiac, Thoracic and Vascular Sciences, University of Padua, Padua, Italy

\section{Edited by:}

Carol Ann Remme, University of

Amsterdam, Netherlands

Reviewed by:

Sebastian Pieperhoff, University of Edinburgh, Scotland

Weinian Shou, Indiana University, USA

${ }^{*}$ Correspondence:

Elisabeth M. Lodder, Department of Experimental Cardiology, Heart

Failure Research Center, Academic

Medical Center, University of

Amsterdam, Meibergdreef 15, Room

L2-107, PO Box 22660, 1100DD

Amsterdam, Netherlands.

e-mail: e.m.lodder@amc.uva.nl
Arrhythmogenic right ventricular cardiomyopathy (ARVC) is a heart muscle disorder characterized by fibro-fatty replacement of cardiomyocytes. The cardinal manifestations are arrhythmias, sudden cardiac death, and seldom heart failure. Mutations in genes encoding desmosomal proteins and their interaction partners have been implicated in the pathogenesis of ARVC and it is now widely accepted that ARVC is a disease caused by abnormal cell-cell adhesion. The mechanism(s) by which mutations in desmosomal proteins lead to fibro-fatty replacement remains to be fully elucidated. To this aim over the last 10 years different transgenic and targeted mouse models have been developed, these models and what they have taught us will be discussed in this review.

Keywords: ARVC, animal models, sudden death, desmosomes

\section{INTRODUCTION}

Arrhythmogenic right ventricular cardiomyopathy (ARVC) is an important cause of ventricular arrhythmias and sudden cardiac death, especially in the young and in athletes (Marcus et al., 1982; Thiene et al., 1988; Basso et al., 2009). Mutations in one or more genes encoding desmosomal proteins are found in $\sim 50 \%$ of patients (McKoy et al., 2000; Rampazzo et al., 2002; Gerull et al., 2004; Pilichou et al., 2006; Syrris et al., 2006). Desmosomes are highly conserved structures that, together with adherens junctions and gap junctions, connect cardiac myocytes end to end at the level of the intercalated disks and thereby play a crucial role in maintaining proper myocardial function (Delmar and McKenna, 2010). Recent findings indicating the presence of mixed type junctions (the area composite; Franke et al., 2006) and crosstalk between protein complexes pertaining to the different types of junctions (Delmar, 2004; Meadows and Isom, 2005; Saffitz, 2005; Tavora et al., 2009; Li and Radice, 2010; Sato et al., 2011) have markedly changed the perception of the intercalated disk. Altered junctional organization, as the result of mutations, is thought to lead to myocardial damage and replacement fibrosis, the classical histopathologic pattern of ARVC (Basso et al., 2009). In advanced stages of the disease, focal scars cause electrical isolation of cardiomyocytes within non-conducting fibrous tissue, resulting in slow conduction and delayed activation, thus forming the substrate for re-entrant circuits and ventricular electrical instability. Over the years several mouse models have been developed to investigate the mechanisms of disease development in ARVC (Pilichou et al., 2011), focusing on four of the desmosomal proteins: Plakophilin-2, Plakoglobin $(\gamma$-catenin), Desmoplakin, and Desmoglein 2. All four will be discussed in detail below; an overview of all the models is given in Table 1.

\section{PLAKOPHILIN-2 TARGETED DELETION}

The first mouse model described that addresses disruption of one of the desmosomal proteins is the study by Grossmann et al. (2004) that describes the targeted deletion of plakophilin-2. The heterozygous mice carrying one wild type copy of plakophilin2 were completely viable without any cardiac phenotype. Mouse homozygous for the deletion ( $\mathrm{Pkp}^{-I-}$ ) died during embryonic development around day 11 post fertilization. Embryos at day 10.5 appeared pale with blood aggregates in the interperitoneal cavity indicating the presence of small holes in the endothelial layers lining the heart and vessels. It would be interesting to see if the Pkp2 ${ }^{ \pm}$ mice develop an ARVC like phenotype upon exercise.

\section{PLAKOGLOBIN TARGETED DELETION AND OVEREXPRESSION MODELS}

The first papers on mouse models involving a desmosomal protein described the targeted deletion of Plakoglobin $(\mathrm{Pg}$ ) by two independent groups in 1996 (models Pg1 and Pg2; Bierkamp et al., 1996; Ruiz et al., 1996). Homozygous targeted deletion of Plakoglobin leads to embryonic lethality between embryonic day 9.5 and 16 due to cardiac malformations: thin cardiac walls and less trabeculation and frequent burst of the epicardial wall; in addition mice showed a blistering skin phenotype. Heterozygous animals appeared healthy and fertile. However, closer inspection of these mice (model Pg2) after the link between ARVC and desmosomal proteins had become clear showed that $\mathrm{Pg}^{ \pm}$mice at 10 months after birth had enlarged right ventricles, increased spontaneous ventricular arrhythmias and right ventricular conduction slowing. No replacement fibrosis and remodeling of the junctions was observed, $\mathrm{Cx} 43$ localization and distribution were normal on immunofluorescence microscopy. All observed changes were exacerbated and expedited when mice were subjected to exercise 
Table 1 | Arrhythmogenic right ventricular cardiomyopathy mouse models.

\begin{tabular}{|c|c|c|c|c|c|}
\hline $\mathbf{N r}$ & Protein & Gene & Mutation/targeted exons & Model type & Reference \\
\hline Pk1 & Plakophilin-2 & Pkp2 & Exon 1-intron 1 & Targeted deletion & Grossmann et al. (2004) \\
\hline Pk2 & Plakophilin-2 & Pkp2 & Exon 1-intron 1 & Targeted deletion & Grossmann et al. (2004) \\
\hline $\operatorname{Pg} 1$ & Plakoglobin & Jup & Exon 2-5 & Targeted deletion & Bierkamp et al. (1996) \\
\hline Pg2-Pg4 & Plakoglobin & Jup & Exon 34 & Targeted deletion & $\begin{array}{l}\text { Ruiz et al. (1996), Kirchhof et al. (2006), } \\
\text { Fabritz et al. (2011) }\end{array}$ \\
\hline Pg5 & Plakoglobin & Jup & Exon 2-3 & Inducible deletion; $\alpha \mathrm{MHC}$ cre induced & Li et al. (2011) \\
\hline Pg6 & $\begin{array}{l}\text { Plakoglobin } \\
\beta \text {-catenin }\end{array}$ & $\begin{array}{l}\text { Jup } \\
\text { Ctnnb1 }\end{array}$ & $\begin{array}{l}\text { Exon 2-3 } \\
\text { Exon 2-5 }\end{array}$ & $\begin{array}{l}\alpha \mathrm{MHC} / \mathrm{MerCreMer} \text { tamoxifen induced } \\
\text { double deletion }\end{array}$ & Swope et al. (2012) \\
\hline $\operatorname{Pg} 7$ & Plakoglobin & Jup & Wild type & Flag tagged transgene & Lombardi et al. (2011) \\
\hline Pg8 & Plakoglobin & Jup & $\begin{array}{l}23654 \Delta 2 \\
\text { Truncated }\end{array}$ & Transgene & Lombardi et al. (2011) \\
\hline Dp1 & Desmoplakin & $D s p$ & $\Delta 281-473$ & $\begin{array}{l}\text { Targeted deletion with extra-embryonic } \\
\text { rescue }\end{array}$ & Gallicano et al. (2001) \\
\hline Dp2 & Desmoplakin & $D s p$ & Exon 2 & Inducible deletion; $\alpha \mathrm{MHC}$ cre induced & $\begin{array}{l}\text { Garcia-Gras et al. (2006), Gomes et al. } \\
\text { (2012) }\end{array}$ \\
\hline Dp3 & Desmoplakin & $D s p$ & Wild type & Flag tagged transgene, $\alpha \mathrm{MHC}$ promoter & Yang et al. (2006) \\
\hline Dp4 & Desmoplakin & $D s p$ & $\mathrm{R} 2834 \mathrm{H}$ & Flag tagged transgene, $\alpha \mathrm{MHC}$ promoter & Yang et al. (2006) \\
\hline Dp5 & Desmoplakin & $D s p$ & Q90R & Flag tagged transgene, $\alpha \mathrm{MHC}$ promoter & Yang et al. (2006) \\
\hline Dp6 & Desmoplakin & $D s p$ & V30M & Flag tagged transgene, $\alpha \mathrm{MHC}$ promoter & Yang et al. (2006) \\
\hline Dg1 & Desmoglein 2 & Dsg2 & Wild type & Flag tagged transgene, $\alpha \mathrm{MHC}$ promoter & Pilichou et al. (2009) \\
\hline Dg2 & Desmoglein 2 & Dsg2 & N271S & Flag tagged transgene, $\alpha \mathrm{MHC}$ promoter & Pilichou et al. (2009) \\
\hline Dg3 & Desmoglein 3 & Dsg2 & Exon 4-6 & Targeted deletion & Krusche et al. (2011), Kant et al. (2012) \\
\hline
\end{tabular}

training (model Pg3; Kirchhof et al., 2006). Load reducing therapy is able to prevent these symptoms of $\mathrm{ARVC}$ in $\mathrm{Pg}^{ \pm}$mice (model Pg4; Fabritz et al., 2011).

To circumvent the problem of neonatal lethality, a cardiac specific targeted deletion of Pg was developed under the control of $\alpha$ MHCcre. $P g^{f / f} \alpha$ MHCcre (model Pg5) mice have $~ 30 \%$ of the WT protein as measured by Western blot, no Pg was detectable by immunofluorescence on cardiac sections. Phenotypically these mice largely recapitulate the human ARVC phenotype: cardiac sudden death, progressive dilation, and fibrosis in the cardiac walls (both in the left and the right ventricle) from 2 month onward. No cardiac fat deposition was observed. With transmission electron microscopy the structure of the desmosomes seemed to be disrupted: other desmosomal proteins (e.g., Dsg2) appeared to be absent from the intercalated disk (Li et al., 2011). Cell death in the $P g^{f / f} \alpha M H C c r e$ mice was at least partially through myocyte apoptosis in addition to myocyte necrosis in contrast to mice overexpressing N271S-Dsg2, which mainly showed myocyte necrosis (see below; Pilichou et al., 2006; Li et al., 2011). Interestingly, increased $\beta$-catenin staining was observed at the intercalated disk suggesting partial rescue by this close relative of $\operatorname{Pg}(\gamma$-catenin). To test whether the lack of fast spontaneous death in these mice (model Pg5) was due to a partial rescue by $\beta$-catenin, double-targeted mice were created, carrying both a floxed Pg gene and a floxed $\beta$-catenin locus $\left(P g f / f ; \beta\right.$-catenin $\left.{ }^{f / f}\right)$. Crossing with $\alpha \mathrm{MHC} /$ MerCreMer mice and subsequent tamoxifen injections effected specific targeted deletion. Double-targeted mice (model Pg6) showed a strong arrhythmogenic phenotype, with $100 \%$ of the double-targeted animals dying of sudden cardiac death between 3 and 5 months after tamoxifen injections. In contrast to either single targeted deletion and wild type littermates of which 4-9\% died within 6 months of tamoxifen injection (Swope et al., 2012).

Two lines overexpressing wild type (model Pg7) and mutant (model Pg8) Pg were generated (Lombardi et al., 2011); both showed similar levels of increased incidence of sudden cardiac death, an indication that even moderate levels of overexpression of $P g$ disturb the balance of the mechanical interaction and signaling functions of $\mathrm{Pg}$ independent of the introduced truncating mutation.

\section{DESMOPLAKIN TARGETED DELETION AND OVEREXPRESSION MODELS}

Desmoplakin (Dsp) targeted deletion mice $D s p^{-1-}$ die at embryonic day 6.5 of malformations in the extra-embryonic tissue before assessment of a cardiac phenotype is possible (Gallicano et al., 1998). To overcome this problem the extra-embryonic phenotype was rescued by tetraploid aggregation (model Dp1). The resulting embryos die around embryonic day E11. At E10 they show severe cardiac malformation although desmosomal-like structures appear to be present by transmission electron microscopy. As these mice die well before birth they are obviously unsuitable as a proper model for ARVC (Gallicano et al., 2001). The embryonic lethality of the $D s p^{-1-}$ mice is partially circumvented in the cardiac specific, $\alpha$ MHCcre induced, targeted deletion of Dsp (model Dp2; Garcia-Gras et al., 2006). The homozygous cardiac specific deletion of Dsp leads to embryonic growth arrest at day E10-E12 with embryos that appeared very pale, with no circulating red blood cells in organs. The heart was poorly formed with no chamber specification, $80 \%$ of $D s p^{-1-}$ mice did not survive until delivery. Mice that did survive the embryonic period died within 6 weeks 
after birth. Heterozygous $D s p^{ \pm}$mice developed normally, however adult $D s p^{ \pm}$mice had thin ventricular walls, increased left ventricular diameters and reduced left ventricular ejection fraction. Spontaneous arrhythmias were observed on surface ECG and 4/5 mice developed ventricular arrhythmias after a single ventricular extra stimulus.

A more detailed study of these $D s p^{ \pm}$mice at earlier stages of disease development, when no abnormalities at the surface ECGs could be detected and no evidence of replacement fibrosis could yet be found, showed a significant increase in the activation time and inducible arrhythmias in Langendorff perfused hearts. These results indicate the presence of electrophysiological abnormalities before the onset of overt structural changes (Gomes et al., 2012). However, no electron microscopy was done to exclude the presence of disrupted desmosomes at the ultrastructural level.

Transgenic mice with cardiac overexpression of flag tagged human Dsp cDNA both wild type (WT-Tg, model Dp3) and with a C-terminal mutation (R2834H-Tg, model Dp4) were generated by Yang et al. (2006). Overexpression of Dsp with N-terminal mutations, e.g., V30M (model Dp5) and Q90R (model Dp6) led to embryonic lethality after embryonic day 13.5 due to reduced ventricular wall thickness and ventricular dilatation. R2834H-Tg mice had an increased heart weight/body weight ratio compared to both wild type littermates and Wt-Tg mice. R2834H-Tg hearts showed increased apoptosis and fibrosis along with reduced ventricular function and dilatation of both right and left ventricles. Co-immunoprecipitation indicated the disruption of the interaction between Dsp and Pg. at the ultrastructural level widening of the intercalated disk was observed in Dp4 mice.

\section{DESMOGLEIN OVEREXPRESSION MODELS}

Transgenic mice with cardiac overexpression of flag tagged Dsg2 both wild type (Tg-WT, model Dg1) and N271S-Dsg2 mutant (TgNS, model Dg2) were generated; the murine N271S mutation is the mouse homolog of the human ARVC mutation DSG2-N266S. While mice overexpressing of wild type Dsg2 were indistinguishable from their wild type littermates at 2 months of age, Tg-Ns mice developed spontaneous ventricular arrhythmias, conduction slowing, ventricular dilatation and aneurysms, and replacement fibrosis, leading to sudden cardiac death from a less than 2 weeks of age. The disease process was triggered by myocyte necrosis followed by calcification and fibrous tissue replacement (Pilichou et al., 2009). These findings are consistent with the results obtained in mice carrying a targeted deletion in the extracellular adhesion domain of Dsg2 (model Dg3). Approximately 30\% of the mice homozygous for the mutation survived embryonic development. These mice develop left and right ventricular dilatation, fibrosis, calcification, and spontaneous death similar to the Tg-NS mice (Krusche et al., 2011). Detailed investigation of this model by transmission electron microscopy revealed a widening of the intercellular space at the intercalated disk and loss of desmosomal structure close to macroscopically visible lesions of the heart (Kant et al., 2012).

\section{DISCUSSION AND CONCLUSION}

The diverse mouse models discussed here recapitulate ARVC disease phenotype and have led to several new insights in the etiology of the cardiac phenotype in ARVC patients. The initial targeted deletion of single desmosomal genes, although embryonically lethal, gave fundamental insights in effects of desmosomal gene dysfunction on cardiac function. All the different models surviving embryonic development, recapitulate the human phenotype in the sense of the arrhythmogenicity, replacement fibrosis, and calcification. None of the models show the clear fatty infiltrations seen in human, this is most likely a reflection of the different composition of the extracellular matrix and non-cardiomyocytes interstitial cells in the wild type murine heart, which lacks a significant adipocyte population (Pilichou et al., 2009). In all described mouse models that survive the embryonic period, the disease process is triggered by cardiac cell death upon cardiac stress after birth. However, they are inconsistent considering the type of cell death occurring, with necrosis being the prominent feature in the Desmoglein 2 models (Dg2 and Dg3) and apoptosis (in addition to necrosis) in the plakoglobin models (Pg5 and Pg6). As a consequence of the myocyte death, calcification, and replacement fibrosis occurs leading to reduced cardiac function and ventricular dilatation. This scar formation also provides a substrate for the arrhythmogenic phenotype seen both in human patients and the ARVC mouse models. The study by Fabritz et al. (2011) shows the positive effect of load reducing therapy on disease progression, clearly underwriting the current disease management strategy of discouraging strenuous physical exercise in patients.

Knowledge of the early disease stages would help in designing more effective treatments (Basso et al., 2011). However, the earliest phase of the disease remains thus far elusive due to the early postnatal severe pathogenicity of the phenotype, precluding the effective dissection of the first pathological changes in the affected hearts. The recent study of Gomes et al. suggests the presence of an electrophysiological disturbance before the development of overt cardiomyopathic changes (Kaplan et al., 2004; Gomes et al., 2012). The proposal of electrical disturbances at this early stage of the disease is an attractive one in the light of the recent data showing cross talk between the mechanical junctions, the gap junctions and the $\mathrm{Na}^{+}$channel complex (Sato et al., 2009, 2011) and the presence of arrhythmias early in the disease process in humans (Bauce et al., 2005). Unfortunately, this study fails to examine the desmosomal structure at this specific time point; it would be interesting to see whether there are ultrastructural changes present that cause the observed electrical changes. Furthermore, the electrophysiological data presented lacks sufficient detail (e.g., $\mathrm{Na}^{+}$-current and action potential measurements) to be able to draw definitive conclusions on the nature of the observed early electrical disturbances.

In conclusion, since the discovery a little over a decade ago that the cause of ARVC lies within the cardiac desmosomal complex and its associated proteins, a wealth of knowledge has been build up on the etiology of the disease. The use of the murine transgenic and targeted models has played a pivotal role in this process. The quest to answer the many remaining questions on the first stages of the disease and the search for a good treatment will continue during the next decade, the developed mouse models will undoubtedly play an important role in this process. 


\section{ACKNOWLEDGMENTS}

This project was funded by the Netherlands Heart Foundation (2008B051). During this investigation, Dr. S. Rizzo was a visiting researcher from the University of Padua at the Academic Medical Center, University of Amsterdam, supported by Cardio-Cerebro Vascular Pathology Registry, Veneto Region, Italy.

\section{REFERENCES}

Basso, C., Bauce, B., Corrado, D., and Thiene, G. (2011). Pathophysiology of arrhythmogenic cardiomyopathy. Nat. Rev. Cardiol. 9, 223-233.

Basso, C., Corrado, D., Marcus, F. I., Nava, A., and Thiene, G. (2009). Arrhythmogenic right ventricular cardiomyopathy. Lancet 373, 1289-1300.

Bauce, B., Basso, C., Rampazzo, A., Beffagna, G., Daliento, L., Frigo, G., Malacrida, S., Settimo, L., Danieli, G., Thiene, G., and Nava, A. (2005). Clinical profile of four families with arrhythmogenic right ventricular cardiomyopathy caused by dominant desmoplakin mutations. Eur. Heart J. 26, 1666-1675.

Bierkamp, C., Mclaughlin, K. J., Schwarz, H., Huber, O., and Kemler, R. (1996). Embryonic heart and skin defects in mice lacking plakoglobin. Dev. Biol. 180, 780-785.

Delmar, M. (2004). The intercalated disk as a single functional unit. Heart Rhythm 1, 12-13.

Delmar, M., and McKenna, W. J. (2010). The cardiac desmosome and arrhythmogenic cardiomyopathies: from gene to disease. Circ. Res. 107, 700-714.

Fabritz, L., Hoogendijk, M. G., Scicluna, B. P., Van Amersfoorth, S. C., Fortmueller, L., Wolf, S., Laakmann, S., Kreienkamp, N., Piccini, I., Breithardt, G., Noppinger, P. R., Witt, H., Ebnet, K., Wichter, T., Levkau, B., Franke, W. W., Pieperhoff, S., De Bakker, J. M., Coronel, R., and Kirchhof, P. (2011). Load-reducing therapy prevents development of arrhythmogenic right ventricular cardiomyopathy in plakoglobindeficient mice. J. Am. Coll. Cardiol. 57, 740-750.

Franke, W. W., Borrmann, C. M., Grund, C., and Pieperhoff, S. (2006). The area composita of adhering junctions connecting heart muscle cells of vertebrates. I. Molecular definition in intercalated disks of cardiomyocytes by immunoelectron microscopy of desmosomal proteins. Eur. J. Cell Biol. 85, 69-82.

Gallicano, G. I., Bauer, C., and Fuchs, E. (2001). Rescuing desmoplakin function in extra-embryonic ectoderm reveals the importance of this protein in embryonic heart, neuroepithelium, skin and vasculature. Development 128, 929-941.
Gallicano, G. I., Kouklis, P., Bauer, C., Yin, M., Vasioukhin, V., Degenstein, L., and Fuchs, E. (1998). Desmoplakin is required early in development for assembly of desmosomes and cytoskeletal linkage. J. Cell Biol. 143, 2009-2022.

Garcia-Gras, E., Lombardi, R., Giocondo, M. J., Willerson, J. T., Schneider, M. D., Khoury, D. S., and Marian, A. J. (2006). Suppression of canonical Wnt/beta-catenin signaling by nuclear plakoglobin recapitulates phenotype of arrhythmogenic right ventricular cardiomyopathy. $J$. Clin. Invest. 116, 2012-2021.

Gerull, B., Heuser, A., Wichter, T., Paul, M., Basson, C. T., Mcdermott, D. A., Lerman, B. B., Markowitz, S. M., Ellinor, P. T., Macrae, C. A., Peters, S., Grossmann, K. S., Drenckhahn, J., Michely, B., Sasse-Klaassen, S., Birchmeier, W., Dietz, R., Breithardt, G., Schulze-Bahr, E., and Thierfelder, L. (2004). Mutations in the desmosomal protein plakophilin2 are common in arrhythmogenic right ventricular cardiomyopathy. Nat. Genet. 36, 1162-1164.

Gomes, J., Finlay, M., Ahmed, A. K., Ciaccio, E. J., Asimaki, A., Saffitz, J. E., Quarta, G., Nobles, M., Syrris, P., Chaubey, S., Mckenna, W. J., Tinker, A., and Lambiase, P. D. (2012). Electrophysiological abnormalities precede overt structural changes in arrhythmogenic right ventricular cardiomyopathy due to mutations in desmoplakin-A combined murine and human study. Eur. Heart J. doi: 10.1093/eurheartj/ehr472. [Epub ahead of print].

Grossmann, K., Grund, C., Huelsken, J., Behrend, M., Erdmann, B., Franke, W., and Birchmeier, W. (2004). Requirement of plakophilin 2 for heart morphogenesis and cardiac junction formation. J. Cell Biol. 167, 149-160.

Kant, S., Krull, P., Eisner, S., Leube, R. E., and Krusche, C. A. (2012). Histological and ultrastructural abnormalities in murine desmoglein 2-mutant hearts. Cell Tissue Res. 348, 249-259.

Kaplan, S. R., Gard, J. J., Protonotarios, N., Tsatsopoulou, A., Spiliopoulou, C., Anastasakis, A., Squarcioni, C. P., Mckenna, W. J., Thiene, G., Basso, C., Brousse, N., Fontaine, G., and Saffitz, J. E. (2004). Remodeling of myocyte gap junctions in arrhythmogenic right ventricular cardiomyopathy due to a deletion in plakoglobin
(Naxos disease). Heart Rhythm 1, 3-11.

Kirchhof, P., Fabritz, L., Zwiener, M., Witt, H., Schafers, M., Zellerhoff, S., Paul, M., Athai, T., Hiller, K. H., Baba, H. A., Breithardt, G. Ruiz, P., Wichter, T., and Levkau, B. (2006). Age- and trainingdependent development of arrhythmogenic right ventricular cardiomyopathy in heterozygous plakoglobindeficient mice. Circulation 114, 1799-1806.

Krusche, C. A., Holthofer, B., Hofe, V. Van De Sandt, A. M., Eshkind, L., Bockamp, E., Merx, M. W., Kant, S., Windoffer, R., and Leube, R. E. (2011). Desmoglein 2 mutant mice develop cardiac fibrosis and dilation. Basic Res. Cardiol. 106, 617-633.

Li, D., Liu, Y., Maruyama, M., Zhu, W. Chen, H., Zhang, W., Reuter, S., Lin, S. F., Haneline, L. S., Field, L. J., Chen, P. S., and Shou, W. (2011). Restrictive loss of plakoglobin in cardiomyocytes leads to arrhythmogenic cardiomyopathy. Hum. Mol. Genet. 20 , 4582-4596.

Li, J., and Radice, G. L. (2010). A new perspective on intercalated disc organization: implications for heart disease. Dermatol. Res. Pract. 2010 207835.

Lombardi, R., Da Graca CabreiraHansen, M., Bell, A., Fromm, R. R., Willerson, J. T., and Marian, A J. (2011). Nuclear plakoglobin is essential for differentiation of cardiac progenitor cells to adipocytes in arrhythmogenic right ventricular cardiomyopathy. Circ. Res. 109, 1342-1353.

Marcus, F. I., Fontaine, G. H., Guiraudon, G., Frank, R., Laurenceau, J. L., Malergue, C., and Grosgogeat, Y. (1982). Right ventricular dysplasia: a report of 24 adult cases. Circulation 65, 384-398.

McKoy, G., Protonotarios, N., Crosby, A., Tsatsopoulou, A., Anastasakis, A. Coonar, A., Norman, M., Baboonian, C., Jeffery, S., and Mckenna, W. J. (2000). Identification of a deletion in plakoglobin in arrhythmogenic right ventricular cardiomyopathy with palmoplantar keratoderma and woolly hair (Naxos disease). Lancet 355, 2119-2124.

Meadows, L. S., and Isom, L. L. (2005). Sodium channels as macromolecular complexes: implications for inherited arrhythmia syndromes. Cardiovasc. Res. 67 448-458.

Pilichou, K., Bezzina, C. R., Thiene, G., and Basso, C. (2011). Arrhythmogenic cardiomyopathy: transgenic animal models provide novel insights into disease pathobiology. Circ. Cardiovasc. Genet. 4, 318-326.

Pilichou, K., Nava, A., Basso, C., Beffagna, G., Bauce, B., Lorenzon, A., Frigo, G., Vettori, A., Valente, M., Towbin, J., Thiene, G., Danieli, G. A., and Rampazzo, A. (2006). Mutations in desmoglein-2 gene are associated with arrhythmogenic right ventricular cardiomyopathy. Circulation 113, 1171-1179.

Pilichou, K., Remme, C. A., Basso, C., Campian, M. E., Rizzo, S., Barnett, P., Scicluna, B. P., Bauce, B., Van Den Hoff, M. J., De Bakker J. M., Tan, H. L., Valente, M., Nava, A., Wilde, A. A., Moorman, A. F., Thiene, G., and Bezzina, C. R. (2009). Myocyte necrosis underlies progressive myocardial dystrophy in mouse dsg2-related arrhythmogenic right ventricular cardiomyopathy. J. Exp. Med. 206, 1787-1802.

Rampazzo, A., Nava, A., Malacrida, S., Beffagna, G., Bauce, B., Rossi, V., Zimbello, R., Simionati, B. Basso, C., Thiene, G., Towbin, J. A., and Danieli, G. A. (2002). Mutation in human desmoplakin domain binding to plakoglobin causes a dominant form of arrhythmogenic right ventricular cardiomyopathy. Am. J. Hum. Genet. 71, 1200-1206.

Ruiz, P., Brinkmann, V., Ledermann, B., Behrend, M., Grund, C., Thalhammer, C., Vogel, F., Birchmeier, C., Gunthert, U., Franke, W. W., and Birchmeier, W. (1996). Targeted mutation of plakoglobin in mice reveals essential functions of desmosomes in the embryonic heart. J. Cell Biol. 135, 215-225.

Saffitz, J. E. (2005). Dependence of electrical coupling on mechanical coupling in cardiac myocytes: insights gained from cardiomyopathies caused by defects in cell-cell connections. Ann. N. Y. Acad. Sci. 1047, 336-344.

Sato, P. Y., Coombs, W., Lin, X., Nekrasova, O., Green, K. J., Isom, L. L., Taffet, S. M., and Delmar, M. (2011). 
Interactions between ankyrin-G, plakophilin-2, and connexin 43 at the cardiac intercalated disc. Circ. Res. 109, 193-201.

Sato, P. Y., Musa, H., Coombs, W., Guerrero-Serna, G., Patino, G. A., Taffet, S. M., Isom, L. L., and Delmar, M. (2009). Loss of plakophilin2 expression leads to decreased sodium current and slower conduction velocity in cultured cardiac myocytes. Circ. Res. 105, 523-526.

Swope, D., Cheng, L., Gao, E., Li, J., and Radice, G. L. (2012). Loss of cadherin-binding proteins betacatenin and plakoglobin in the heart leads to gap junction remodeling and arrhythmogenesis. Mol. Cell. Biol. 32, 1056-1067.
Syrris, P., Ward, D., Asimaki, A., SenChowdhry, S., Ebrahim, H. Y., Evans, A., Hitomi, N., Norman, M., Pantazis, A., Shaw, A. L., Elliott, P. M., and Mckenna, W. J. (2006). Clinical expression of plakophilin2 mutations in familial arrhythmogenic right ventricular cardiomyopathy. Circulation 113, 356-364.

Tavora, F., Creswell, N., and Burke, A. P. (2009). Arrhythmogenic right ventricular cardiomyopathy. N. Engl. J. Med. 360, 2784. [author reply 2785-2786].

Thiene, G., Nava, A., Corrado, D., Rossi, L., and Pennelli, N. (1988). Right ventricular cardiomyopathy and sudden death in young people. N. Engl. J. Med. 318, 129-133.
Yang, Z., Bowles, N. E., Scherer, S. E., Taylor, M. D., Kearney, D. L., Ge, S., Nadvoretskiy, V. V., Defreitas, G., Carabello, B., Brandon, L. I., Godsel, L. M., Green, K. J., Saffitz, J. E., Li, H., Danieli, G. A., Calkins, H., Marcus, F., and Towbin, J. A. (2006). Desmosomal dysfunction due to mutations in desmoplakin causes arrhythmogenic right ventricular dysplasia/cardiomyopathy. Circ. Res. 99, 646-655.

Conflict of Interest Statement: The authors declare that the research was conducted in the absence of any commercial or financial relationships that could be construed as a potential conflict of interest.
Received: 16 April 2012; paper pending published: 26 April 2012; accepted: 02 June 2012; published online: 21 June 2012.

Citation: Lodder EM and Rizzo S (2012) Mouse models in arrhythmogenic right ventricular cardiomyopathy. Front. Physio. 3:221. doi: 10.3389/fphys.2012.00221

This article was submitted to Frontiers in Cardiac Electrophysiology, a specialty of Frontiers in Physiology.

Copyright $(9) 2012$ Lodder and Rizzo. This is an open-access article distributed under the terms of the Creative Commons Attribution Non Commercial License, which permits non-commercial use, distribution, and reproduction in other forums, provided the original authors and source are credited. 